Indexed by:

Csinta

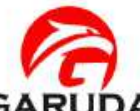

GARUDA

Crossref

Crossmark

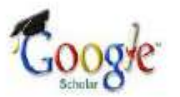

Dimensions

Oonesearch

Manuscripts screening tools:

turnitin $\square$

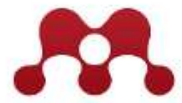

MENDELEY

\section{KARAKTERISTIK DAN MAKNA TERITORI TERAS RUMAH BERLABUH MASYARAKAT SERUI ANSUS (Studi Kasus permukiman rumah berlabuh masyarakat Serui Ansus Kota Sorong, Papua Barat)}

Devy Sarah Sahambangun

Program Studi Teknik

Arsitektur, Universitas Prisma,

J1. Pomurow No. 133 Lingkungan III

Manado, Sulawesi Utara, Indonesia

95126
Kota Manado, Indonesia

\section{Dwars Soukotta}

Program Studi Teknik Arsitektur, Universitas Prisma, Kota Manado, Indonesia J1. Pomurow No. 133 Lingkungan III Manado, Sulawesi Utara, Indonesia 95126

\section{Key words:}

Characteristics, Territorial Space, Terrace, Settlement of Serui Ansus Community

Doi:

10.17509/jaz.v4i1.30087

Cite article:

Sahambangun, D. S., dan Soukotta, D. (2021). Karakteristik dan Makna Teritori Teras Rumah Berlabuh Masyarakat Serui Ansus (Studi Kasus permukiman rumah berlabuh masyarakat Serui Ansus Kota Sorong, Papua Barat). Jurnal Arsitektur Zonasi, 4(1), 105-113. https://doi.org/doi.org/10.17509/jaz.v4i1.30087

G grammarly 
http://ejournal.upi.edu/index.php/jaz - e-mail: jurnal_zonasi@upi.edu doi.org/10.17509/jaz.v4i1.30087

\section{KARAKTERISTIK DAN MAKNA TERITORI TERAS RUMAH BERLABUH MASYARAKAT SERUI ANSUS

\author{
(Studi Kasus permukiman rumah berlabuh masyarakat Serui Ansus Kota Sorong, Papua Barat)
}

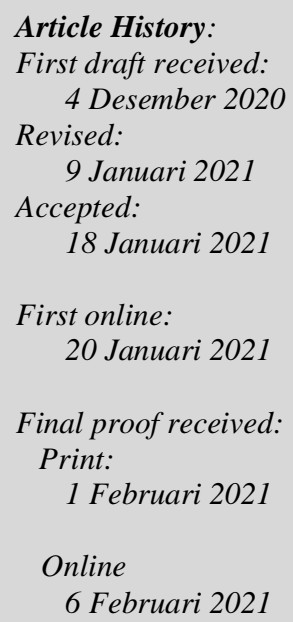

Jurnal Arsitektur ZONASI is indexed and listed in several databases:

SINTA 4 (Arjuna)

GARUDA (Garda Rujukan Digital) Google Scholar

Dimensions

oneSearch

BASE

Member:
Crossref
RJI
APTARI
FJA (Forum Jurna Arsitektur)
IAI
AJPKM

\author{
Devy Sarah Sahambangun ${ }^{I}$ \\ Dwars Soukotta $^{2}$ \\ 1,2 Program Studi Teknik Arsitektur, Universitas Prisma, Manado, Indonesia \\ Jl.Pomorow No. 113 Lingkungan III Manado 95126, Sulawesi Utara, Indonesia \\ Email : ${ }^{1}$ sarah.vyrah@gmail.com ; ${ }^{2}$ dwarssoukotta@gmail.com
}

\begin{abstract}
Terrace is a transitional space into the house in general which functions as a waiting room or a place to relax. However, at the rumah berlabuh settlement of Serui Ansus community, the terrace has more functionality than the lounge or waiting room because the houses are above sea level. The terrace functions as a central point for many activities. The shape of the territory as an area for different activities is an interesting point for further research. This builds upon the research of the Community Settlement Pattern of Serui Ansus (2014). This study Used a qualitative descriptive method, the data used is the result of case study observations with a sign language approach and open interviews in case studies on rumah berlabuh settlements of the Serui Ansus community in Klademak 2 Village, Sorong City. The results of this study indicate that the pattern of coastal settlements built on water forms a pattern of activities that occur on the space terrace with various activities, which form the characteristics and meaning of the terraced territorial spaces in the Serui Ansus settlement. There are 3 characteristics of the terrace shape with 3 models of boundary patterns with different meanings. Some of the terraces in some case studies are primary territories, but there are terraces that are secondary territories or are used by a group of people for socializing.
\end{abstract}

Keywords: Characteristics, Territorial Space, Terrace, Settlement of Serui Ansus Community

\begin{abstract}
Abstrak: Teras merupakan ruang peralihan dari luar ke dalam rumah pada umumnya yang memiliki fungsi sebagai ruang tunggu atau sebagai tempat bersantai tempat bersantai. Pada permukiman rumah berlabuh Masyarakat Serui Ansus, teras memiliki fungsi lebih dari ruang tunggu atau ruang santai, hal ini dikarenakan rumah-rumah tersebut berada di atas permukaan air laut, sehingga teras berfungsi sebagai halaman rumah dengan begitu banyak kegiatan. Bentuk ruang teritori sebagai penanda batas wilayah dengan berbagai aktivitas yang berbeda menjadi hal menarik untuk di kaji. Penelitian ini merupakan pengembangan dari penelitian Pola permukiman Masyarakat Serui Ansus (2014) mengunakan metode deskriptif kualitatif, data yang digunakan merupakan data hasil observasi study kasus dengan pendekatan bahasa tanda serta wawancara terbuka pada lokasi permukiman berlabuh masyarakat Serui Ansus di Kecamatan Klademak 2 Kota Sorong. Hasil dari penelitian ini menunjukan bahwa pola permukiman pesisir yang dibangun diatas air membentuk pola aktivitas yang terjadi pada teras ruang dengan berbagai macam kegiatan yang membentuk karakteristik dan makna ruang teritori teras di permukiman Serui Ansus, dimana terdapat 3 karakteristik bentuk teras dengan 3 model pola pembatas dengan makna yang berbeda. sebagian ruang teras pada beberapa studi kasus merupakan teritori primer tetapi terdapat teras yang menjadi tertirori sekunder atau digunakan oleh sekelompok masyarakat untuk bersosialisasi.
\end{abstract}

Kata Kunci: Karakteristik, Ruang Teritori, Teras, Permukiman Masyarakat Serui Ansus

\section{Pendahuluan}

Masyarakat pesisir di Indonesia memiliki banyak keunikan yang menarik untuk dipelajari. Masingmasing suku yang tinggal di pesisir mempunyai cara tersendiri untuk memaknai ruang-ruang pada rumah 
tinggal maupun ruang-ruang komunal di sekitar tempat tinggal mereka, Salah satunya masyarakat Serui Ansus yang merupakan suku yang berasal dari tanah Papua, berasal dari pulau Yapen, yang banyak tersebar di hampir seluruh pesisir di Tanah Papua. Dengan majunya pembangunan di Tanah Papua, pemerintah berupaya untuk menyedakan fasilitas rumah tinggal bagi masyarakat lokal, akan tetapi kebanyak dari masyarakat setempat tidak mau menempati hasil pembangunan permukiman yang dibangun oleh pemerintah. Bahkan pada kasus tertentu permukiman yang disediakan oleh pemerintah di daratan, masyarakat yang biasa mendiami permukiman rumah berlabuh memilih untuk mengambil bahan bangunan seperti atap dan kayu untuk dipindahkan ketempat yang mereka inginkan, yang lebih cocok dengan kehidupan keseharian mereka, disamping rawa atau di pesisir pantai dengan akses lebih cepat ke tempat mereka mencari nafkah dan sudah dilakukan turun temurun dari leluhur mereka. Sangat penting untuk mengetahui bagaimana bentuk2 dan polapola keruangan masyarakat pesisir khususnya permukiman rumah berlabuh agar dapat merencanakan lokasi dan bentuk permukiman yang tepat.

Penelitian ini khusus membahas teras yang merupakan bagian yang sangat penting dalam kehidupan masyarakat yang mendiami permukiman rumah berlabuh, dimana teras menandakan ruang terirori yang menjadi bentuk nyata dari wilayah privat atau kelompok, dan menjadi bentuk dari cara suatu kelompok memaknai ruang mereka dan juga memiliki fungsi yang sangat besar untuk masing-masing rumah berlabuh. Pada permukiman rumah berlabuh Masyarakat Serui Ansus, teras memiliki fungsi lebih dari ruang tunggu atau ruang santai, hal ini dikarenakan rumah-rumah tersebut berada di atas permukaan air laut, sehingga teras berfungsi sebagai halaman rumah dengan begitu banyak kegiatan. Bentuk ruang teritori sebagai penanda batas wilayah dengan berbagai aktivitas yang berbeda. Rumusan masalah penelitian ini yaitu: bagaimana bentuk karakteristik dan makna ruang teritori rumah berlabuh masyarakat serui ansus, serta hal apa yang dapat menjadi pertimbangan bagi perencanaan dan perancangan rumah yang direncanakan oleh pemerintah.

\section{Tinjauan Pustaka}

\subsection{Rumah berlabuh masyarakat serui ansus}

Rumah berlabuh (Sahambangun et al., 2014) merupakan sebutan umum yang digunakan oleh masyarakat Papua untuk bentuk rumah panggung yang dibangun di atas air. Masyarakat asli Serui Ansus menyebutnya sebagai "Manu Awoi" untuk kelompok rumah yang berada di laut dan "manu dewoi" jika hanya terdapat 1 rumah. Manu artinya Rumah, sedangkan Awoi (jamak) dan Dewoi (tunggal) artinya berlabuh, Jika rumah tersebut berada di atas laut ditambahkan Airau artinya di laut. Sehingga permukiman pesisir masyarakat Serui Ansus dalam bahasa mereka adalah "Manu Awoi Airau”. Sahambangun menguraikan bahwa rumah ini menjadi tempat tinggal nelayan masyarakat serui ansus untuk memudahkan akses ketempat mereka bekerja, dibuat dari pengetahuan turun-temurun, dengan tiang kolong rumah menggunakan kayu mangi-mangi yang dipancang dengan kedalaman $2 \mathrm{~m}$, dan tinggi dari pemukaan pasir laut 2-3.5 $\mathrm{m}$, bagian kolom dan balok dasar rumah diikat. Struktur ikat pada tiang pondasi rumah untuk memudahkan pergantian struktur kolom yang rusak atau lapuk. dinding rumah terbuat dari kulit sagu dan kayu mangi-mangi, lantai kulit sagu, dan atap dari daun sagu atau daun nipa.

Seiring berkembangnya ilmu pengetahuan dan teknologi rumah tradisional ini bergeser pada bentuk dan material yang lebih modern dimana bahan pembuat lantai, dinding dan atap diganti mengikuti perkembangan jaman dan dengan alasan lebih praktis, material pembuat lantai tidak lagi mengunakan kulit sagu atau kayu mangi-mangi, tetapi mengunakan papan kayu, dan atap menggunakan seng. Tetapi cara mendirikan rumah secara tradisional tetap dipertahankan. Masyarakat Serui Ansus memiliki kecenderungan untuk memisahkan ruang dengan suku lain yang ada di dalam permukiman, sehingga muncul ruang yang tidak diinginkan karena perbedaan suku, dimana masyarakat Serui Ansus menginginkan teritori yang lebih privat yang membatasi adanya kehadiran suku-suku lain di ruang publik mereka. Menurut Sahambangun et al., (2015) Rumah berlabuh masyarakat serui yang mencerminkan cara mereka hidup dan memaknai arti ruang yang terbentuk oleh faktor budaya, kebutuhan dan aktifitas seperti beribadah, bekerja, bermain dan beristirahat. Fungsi ruang tidak terikat pada bentuk dan jenis ruang seperti pada rumah pada umumnya, melainkan terikat pada aktifitas yang dilakukan oleh masyarakat serui dan cara mereka memaknai arti sebuah ruang seperti yang terjadi pada fungsi kamar tidur dan ruang tamu. Bentuk teritori merupakan strategi keruangan masyarakat serui ansus untuk memaknai siapa saja yang berhak beraktivitas di teritori mereka, dan perluasan area teritori merupakan cara mereka bertahan dari perubahan-perubahan disekitar mereka, dimana tempat tinggal mereka sudah banyak di kuasai oleh pendatang yang bukan dari suku Serui Ansus (Sahambangun et al., 2015). 


\subsection{Ruang teritori}

Menurut Laurens, 2004 teritorial merupakan salah satu hubungan antar pola tingkah laku dengan hak kepemilikan seseorang atau kelompok atas suatu tempat. Teritorial ini merupakan wilayah yang dianggap sudah menjadi hak seseorang. Teritori juga dapat terlihat berdasarkan batas-batas ruang yang sebenarnya dan menjadi tanda kepemilikan (Kärrholm, 2016)

Lawson, 2007 menjelaskan bahwa terirori bukan hanya sebuah konsep ruang, tetapi juga sebuah fenomena sosial. Faktanya, area teritori dapat menjadi sebuah pertimbangan untuk posisi dan lokasi untuk ruang dari suatu masyarakat atau kelompok. Lima indikasi karakter dari ruang perikalu yaitu: halaman rumah, ruang aktivitas utama, teritori, teritori temporer, dan ruang privat (Rapoport, 1977)

Altman, 1975 mengeneralisasikan kategori teritori sebagai berikut:

a. Terirori primer: teritori primer berada di bawah kepemilikan eksklusif dan penggunaan orang atau kelompok tertentu di mana seseorang memiliki kontrol yang kuat. Lingkup kelompok ini meliputi istri dan suami, individu atau keluarga. Arti rasa dari teritorial jenis ini bersifat permanen dan termasuk ke dalam kelompok.

b. Teritori sekunder: teritori yang dimiliki dan digunakan oleh individu atau kelompok tetapi memiliki kualitas publik, di mana orang lain juga memiliki akses. Kepemilikan dalam tipe ini didefinisikan melalui unit sekunder yang mana individu tersebut dianggap sebagai bagian dari suatu kelompok. Kepemilikan wilayah ini bersifat jangka panjang.

c. Teritori publik: teritori ini memiliki cakupan sementara dan dapat diakses hampir oleh semua orang. Selama beberapa norma social masih dianggap, wilayah ini dapat digunakan oleh semua orang. Kepemilikan jenis ini digeneralisasi ke unit-unit publik yang mencakup kelompok yang lebih speader dan lebih luas. Kepemilikan atas jenis wilayah ini bersifat jangka pendek.

\subsection{Ruang Teritori pada Permukiman}

Soukotta (2014) mengidentifikasi penggunaan tanda berupa elemen-elemen lingkungan alami berupa tumbuhan dan elemen lingkungan binaan berupa perabot untuk menandai area teritori primer sebagai tanda yang jelas antar keluarga atau antar rumah pada rumah-rumah di Kampung Jawa-Tondano Lingkungan III. Ruang teritori Publik pada Rumah-Rumah Kampung Jawa Tondano berupa Teras, halaman rumah, warug dan toilet dikarenakan Kampung Jawa Tondano merupakan hasil alkulturasi budaya Jawa dan Minahasa, dimana budaya hidup rukun antar sesama warga selalu dijaga melalui aturan kampung secara tidak tertulis yakni hidup bertetangga tidak dibatasi oleh pagar pembatas, sehingga ruang teritori primer berubah menjadi teritori publik (Soukotta et al., 2014).

Pada penelitian teritori permukiman Kampung Melayu (Amalia \& Amal, 2019) Batas teriori yang terbentuk secara fisik dan non fisik merupakan kontrol ruang penghuni terhadap ruang luarnya yang tersetting karena aktivitas, persepsi dan legalitas serta orientasi hunian. Karakteristik teritorialitas ruang memiliki bentuk dan pola berbeda-beda tergantung aktivitas, waktu, latar belakang budaya dan lama menetap masyarakat di Permukiman Kampung Melayu.

Bawembang et al., (2017) mengidentifikasi teritori dalam ruang publik di kampung Cina terkait dengan budaya dan kepercayaan yang mereka bawa. Teritori primer terletak pada area perdagangan jasa, pertokoan yang walaupun bersifat publik pada waktu tertentu, tanda teritori primer tetap diwujudkan di area ini. Teritori sekunder ditemukan di area pedestrian, parkir, tempat ibadah atau di area-area peralihan sedangkan teritori publik ditemukan di semua kawasan kampung Cina karena peruntukannya untuk komersil namun diatur dengan aturan-aturan yang berlaku di kawasan kampung Cina.

Pemakaian teras yang fleksibel merupakan salah satu alasan terbentuknya teras. Teritori teras dapat tercipta dari pola perilaku penghuni yang melakukan kegiatan di teras yang berulang dan konstan. Lokasi penelitian berada di daerah pesisir kampung Bansir Laut, Kecamatan Pontianak tenggara, Kalimantan Barat. Topologi permukiman kampung Bansir yang merupakan permukiman pinggiran sungai memiliki karakter permukiman yang dibangun diatas air. Teritori yang tidak jelas karena rumah yang didirikan berada diatas air merupakan alasan pemilik rumah membentuk suatu penanda atau batasan teritori rumahnya. Berdasarkan alasan tersebut dibentuklah teritori teras yang disesuaikan dengan kebutuhan dan mendukung aktivitas dalam teras. Permukiman kampung Bansir yang merupakan permukiman multi etnis dan berada di pesisir sungai, meciptakan pola perilaku yang khas dan dipengaruhi oleh keberadaan sungai Kapuas. Sehingga menciptakan karakteristik setting-setting tipe teras yang sama, namun memiliki fungsi teras yang berbeda (Nurhamsyah \& Saputro, 2016). 


\section{Metode Penelitian}

Metode yang digunakan pada penelitian ini adalah metode deskriptif kualitatif, menggunakan pedekatan Penelitian Rasionalisme. Penelitian ini dilakukan di kelurahan Klademak 2, Kota Sorong dengan study kasus 8 rumah berbeda. Data diperoleh dengan teknik wawancara terbuka, dan observasi dan dokumentasi bahasa tanda pada ruang-ruang teras rumah berlabuh yang memiliki makna ruang teritori. analisa data difokuskan pada bentuk karakteristik teras dan analisis makna dari bahasa tanda pada ruang teritori teras.

\section{Hasil dan Pembahasan}

Teras yang merupakan area transisi dari luar ke dalam rumah yang dibangun di atas tanah, pada umumnya berfungsi sebagai area tunggu atau ruang santai, namun pada permukiman yang dibangun di atas permukaan air laut, teras berfungsi lebih dari itu. Banyak kegiatan seperti tempat usaha, tempat penyimpanan, tempat bersosialisasi dan berbagai akfititas lainnya. Fungsi teras yang sangat penting bagi pemukiman berlabuh juga diikuti berbagai mekanisme mengatur batas area rumah, dengan kontrol ruang yang jelas. Hal ini menandakan bahwa terdapat pola karakteristik ruang teritori pada teras rumah berlabuh masyarakat serui ansus. Adanya aktifitas yang berulang dengan tanda-tanda teritori menjadi hal yang menarik untuk diteliti.

\section{1. karakteristik teras}

Karakter bentuk teras rumah berlabuh masyarakat Serui Ansus yang ada dilokasi penelitian 1, 2 dan 3 dibagi atas 4 jenis, yaitu:

a. rumah yaitu rumah dengan teras depan dan belakang, rumah dengan teras di sekeliling rumah,

b. rumah dengan teras depan dan belakang serta 1 teras samping.

c. rumah dengan teras depan dan teras belakang.

Namun terdapat perbedaan antara lokasi penelitian 1 dengan lokasi penelitian 2 dan 3 . Perbedaannya hanya pada posisi pintu masuk dari jembatan penghubung. Pada lokasi permukiman 1 pintu masuk tidak langsung menghadap jembatan tetapi berada pada samping rumah. Sedangkan pada lokasi penelitian 2 dan 3 pintu masuk langsung menghadap jembatan (lihat Tabel 1).

Tabel 1. Karakteristik teras pada rumah berlabuh studi kasus rumah berlabuh

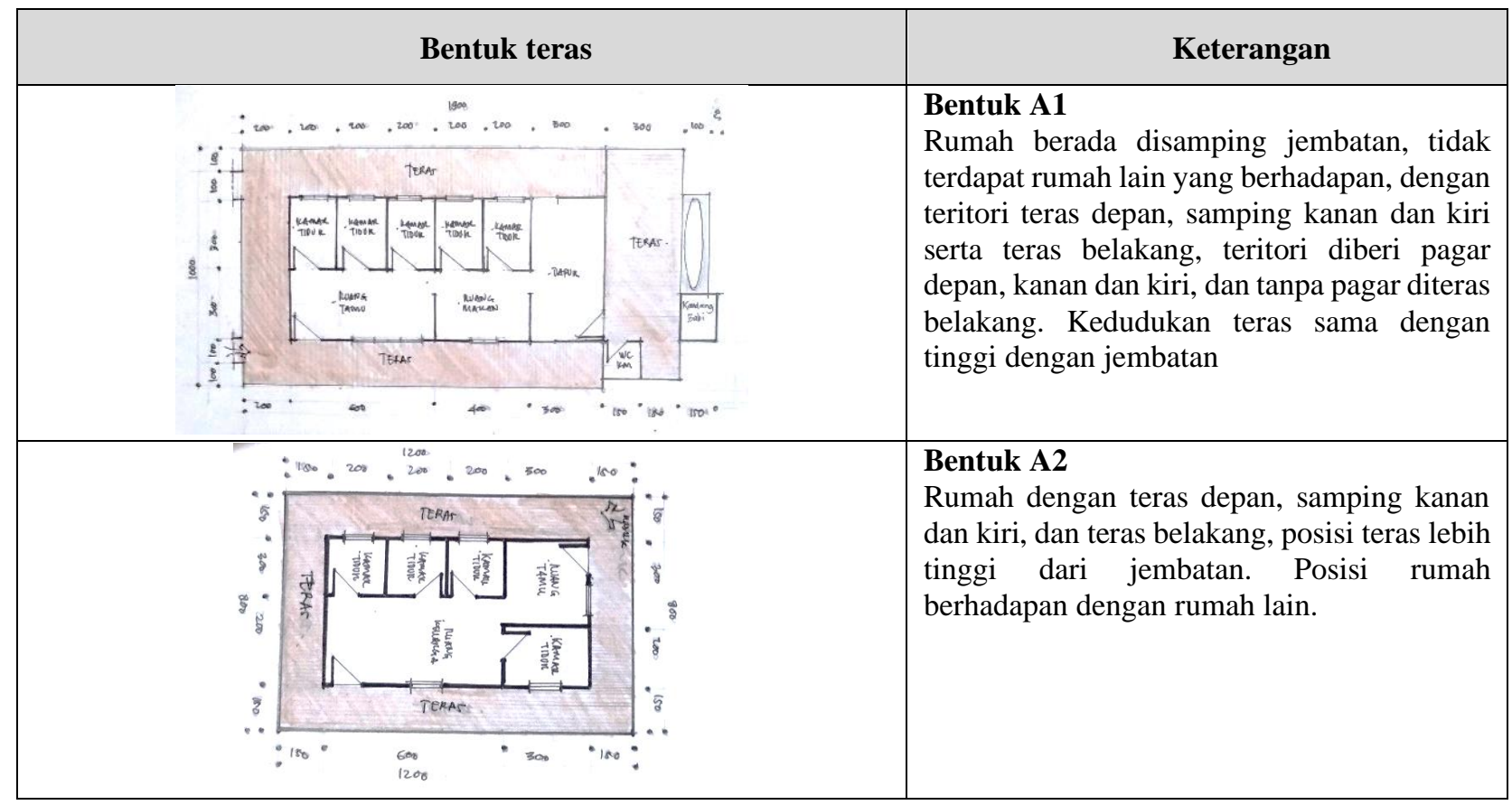




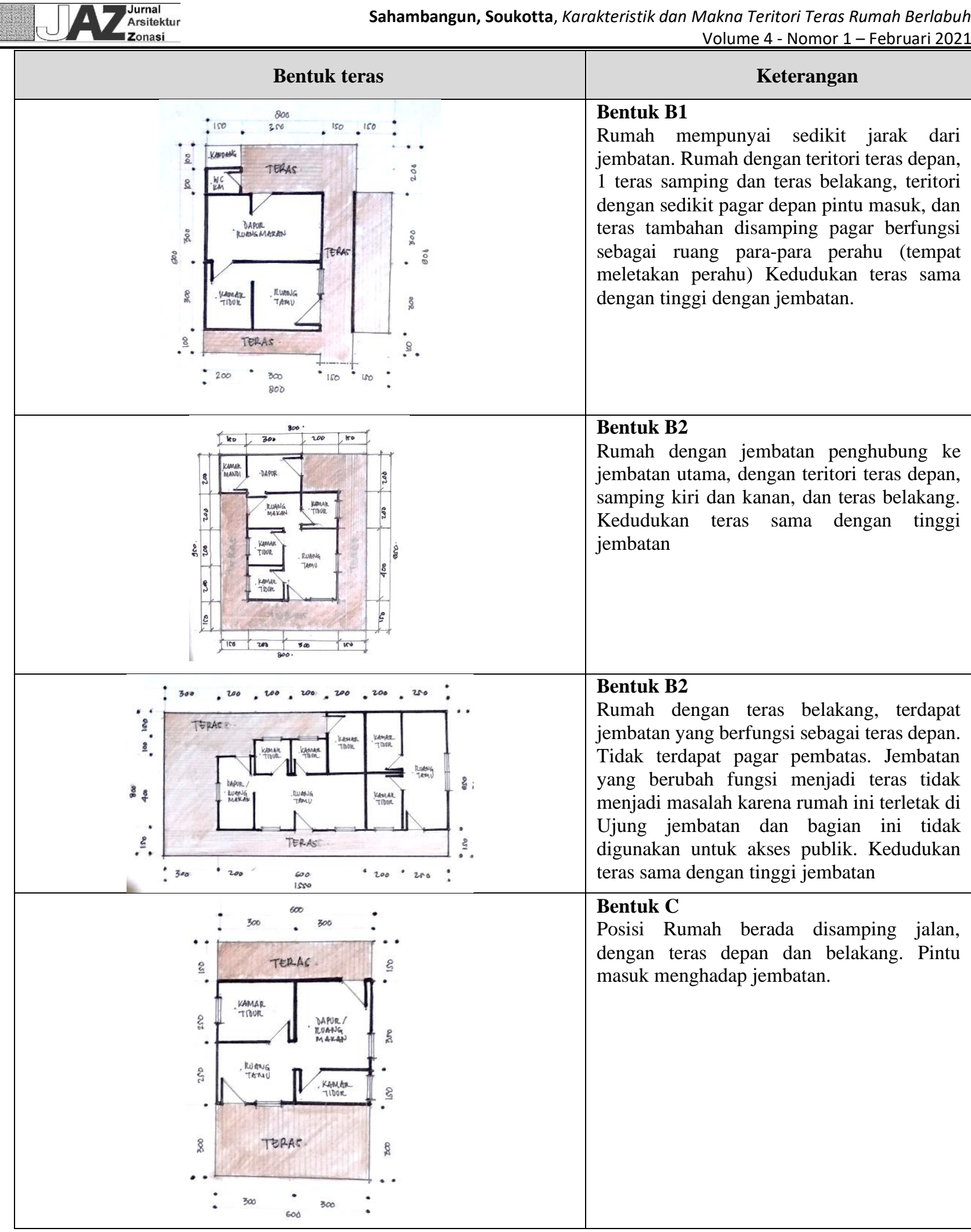

\subsection{Elemen penandaan teritori teras pada permukiman}

Sumber: Dokumen penulis, 2020

Elemen penandaan teritori teras pada permukiman rumah berlabuh dibagi atas 2 bagian, yang pertama berdasarkan perletakan barang, yang kedua berdasarkan elemen pembatas dan kedudukan teras terhadap jembatan(jalan kompleks).

\section{a. Tanda perletakan barang.}

Perletakan barang pada ruang teras di permukiman berlabuh merupakan bentuk dari makna fungsi teras. Sebagian besar teras pada lokasi penelitian memiliki multi fungsi, mulai dari fungsi zona entrance, ruang 
servis, dan ruang semi privat. Pada Rumah-rumah studi kasus penelitian terdapat teras yang diberikan naungan atap dan ada yang tanpa atap, fungsi dari teras tersebut dapat dilihat pada tabel 2 .

Tabel 2. Penanda ruang teritori dan Makna ruang pada teras rumah berdasarkan tanda perletakan barang/

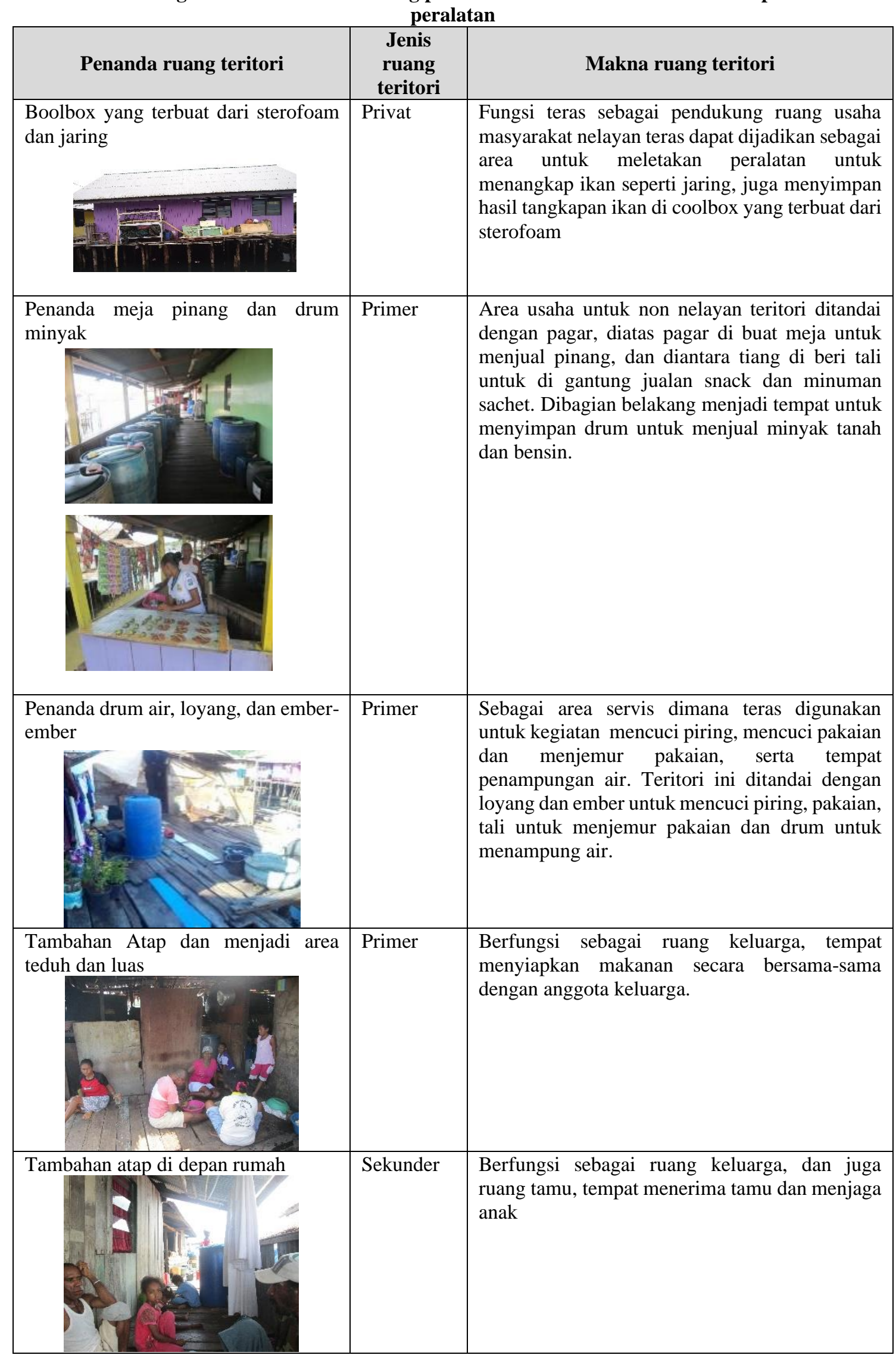




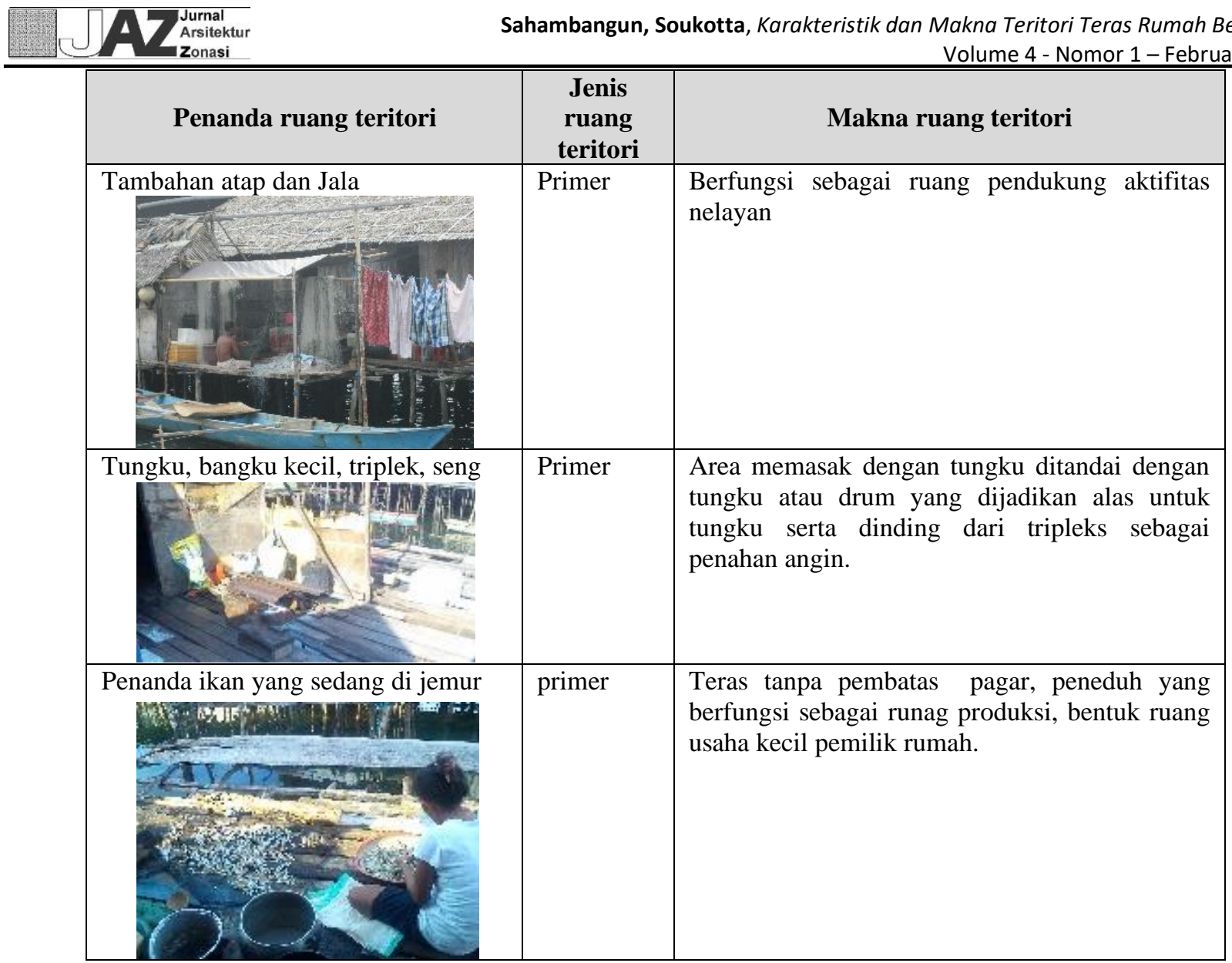

b. Bentuk-bentuk penanda ruang teritori berdasarkan pembatas rumah berlabuh Masyarakat Serui Ansus Rumah-rumah di permukiman masyarakat serui ansus kebanyakan memiliki teras yang cukup luas, berikut ini diurakai bentuk tanda pembatas ruang teritori teras:

1. Sebagian rumah berlabuh di Permukiman Serui Ansus, menandai teritori teras rumah dengan pagar pembatas semi permanen pada bagian depan dan samping, yang berfungsi sebagai pelidung tanaman dan juga pembatas karena menjadi ruang usaha.

2. Semua teritori teras rumah tidak memiliki pagar pembatas pada bagian belakang untuk memudahkan aktifitas membeli air minum dari penjual air minum yang mengunakan perahu serta memudahkan aktivitas untuk mengangkut peralatan nelayan maupun hasil tangkapan nelayan. Hal ini juga didukung karena semua rumah memiliki akses masuk perahu di bagian belakang rumah. Juga merupakan area produksi ikan kering untuk usaha kecil rumah tangga, teras yang tidak diberi pembatas memberikan akses cahaya matahari lebih banyak sehingga proses pengeringan ikan berlangsung dengan baik.

3. Rumah dengan teritori teras terbuka tanpa pagar pembatas dengan kedudukan yang sama tinggi dengan jembatan, memiliki pagar maupun tidak lebih bersifat teritori primer. Sedangkan rumah yang kedudukan teras lebih tinggi dari jembatan dengan posisi berhadapan memiliki fungsi sebagai ruang sosial dan berubah menjadi teritori sekunder yang digunakan oleh kelompok masyarakat dijembatan itu.

\subsection{Makna teritori teras berdasar penanda ruang}

Teras pada rumah berlabuh permukiman masyarakat Serui Ansus ada yang berfungsi sebagai ruang teritori primer dan ada yang menjadi ruang teritori sekunder. Rumah-rumah pada jembatan 1 di lokasi penelitian memiliki pagar pembatas tidak saling berhadapan dan pintu rumah tidak langsung menghadap jalan memberikan kesan lebih privasi. Pada lokasi jembatan 3, terdapat rumah dengan pagar pembatas untuk menjaga tanaman yang letakan di teras agar tidak terjatuh atau terganggu dengan orang yang lalu lalang. Beberapa teritori primer juga ditendai dengan posisi rumah terhadap jalan. Rumag tanpa pagar pembatas namun memiliki jembatan penghubung dengan jembatan utama memberikan makna teritori yang lebih privat. Namun Area teritori sekunder pada teras rumah berlabuh ditandai dengan posisi dan lokasi untuk ruang teras rumah yang berhadapan langsung dengan jalan utama (jembatan kompleks) dengan posisi teras tanpa pagar 
pembatas lebih tinggi jalan dengan jarak hadapan rumah sangat dekat membentuk ruang duduk dengan area teduh yang memungkinkan terjadinya ruang untuk masyarakat dikompleks jembatan itu saling bersosialisasi, kegiatan bersama seperti perbincangan sampai kegiatan tidur yang seharusnya dilakukan diruang privat terjadi disini. Hal ini dikarenakan adanya rasa aman pengguna ruang karena ruang ini menjadi ruang teritori kelompok/sekunder (masyarakat serui ansus) Fakta menarik ditemui di lokasi penelitian kompeks jembatan 3, dimana teras yang merupakan teritori privat, bisa berubah fungsi menjadi ruang para-para tempat duduk warga untuk berkumpul dan bersosialisasi, sehingga menjadi teritori sekunder.

Hampir semua ruang teras yang berada di belakang rumah menjadi teritori primer dikarena bagian belakang rumah hanya bisa diakses dengan perahu dan menjadi area penyimpanan air, penyimpanan ikan dan peralatan memancing yang akan menyebabkan agresi jika ruang itu terganggu.

\section{Kesimpulan}

Fungsi teras bagi permukiman rumah berlabuh masyarakat serui ansus bukan hanya sebagai area transisi dari jalan menuju ke dalam rumah, tapi lebih mengarah ke fungsi halaman seperti rumah tinggal diatas tanah dengan bentuk ruang multifungsi. Rumah yang terletak di depan jalan komplek miliki pagar merupakan ruang dengan teritori primer, begitu juga dengan rumah yang memiliki jembatan penghubung dari jembatan utama kompleks bersifat lebih privat, sedangkan rumah yang berhadapan dengan jalan ditengah dengan teras terbuka namun lebih tinggi dari jalan/jembatan menjadi teritori sekunder.

Ruang teritori teras ditandai dengan coolbox, peralatan memancing, jemuran ikan kering menjadi makna kegiatan matapencaharian masyarakat Serui Ansus. Sedangkan teritori teras yang ditandai jarak tinggi teras dari jalan pada rumah yang saling berhadapan menjadi teritori sekunder dengan berbagai aktifitas bersosialisasi kelompok. Berdasarkan kesimpulan, peneliti menyarankan;

1. Dalam melakukan perancangan permukiman masyarakat lokal khususnya serui ansus, bentuk-bentuk teras ini perlu dimasukan sebagai pertimbangan dalam desain, dimana merencanakan rumah dengan teras/halaman depan samping dan belakang yang bisa memberikan privasi tapi juga bisa menjadi ruang bersosialisasi. Penting juga untuk memperhatikan kedudukan permukiman tersebut dari tempat para penguhi rumah bekerja dalam hal ini penghuni yang bermatapecaharian sebagai nelayan yang sangat membutuhkan akses ke lau lebih cepat. dan memiliki area untuk meletakan peralatan melaut mereka dengan aman.

2. Perlu dilakukan penelitian lanjutan yang bisa membahas pola perilaku keseharian masyarakat yang tinggal dipermukiman pesisir dari suku yang lain dengan metode pendekatan ruang teritori sehingga akan lebih banyak wawasan tentang masyarakat pesisir di Indonesia.

\section{Referensi}

Altman, I. (1975). The environment and social behavior: privacy, personal space, territory, and crowding. Brooks/ Cole Pub.

Amalia, A. A., \& Amal, C. A. (2019). Teritorialitas Ruang Pada Permukiman Kampung Melayu Kota Makassar. Jurnal Linears, 1(1), 28-34. https://doi.org/10.26618/j-linears.v1i1.1319

Bawembang, E. N., Kumurur, V. A., \& Waa. (2017). Teritori Dalam Ruang Publik Masyarakat Kampung Cina Di Kota Manado. Jurnal Arsitektur DASENG, 6(1), 32-42.

Kärrholm, M. (2016). Retailising space: Architecture, retail and the territorialisation of public space. In Retailising Space: Architecture, Retail and the Territorialisation of Public Space. https://doi.org/10.4324/9781315605951

Laurens, J. M. (2004). Arsitektur dan Perilaku Manusia. In Arsitektur dan Perilaku Manusia (Vol. 42, Issue 4, pp. 1-237). PT. Grasindo.

Lawson, B. (2001). Language of Space (Google eBook). Architectural Press.

Nurhamsyah, M., \& Saputro, N. M. (2016). Tipe Setting Teritori Teras Akibat Aktivitas Tambahan Penghuni Di Permukiman Pesisir Sungai Kapuas. Langkau Betang: Jurnal Arsitektur, 3(1), 43-56. https://doi.org/10.26418/lantang.v3i1.16721

Rapoport, A. (1977). Human Aspects of Urban Form. In Human Aspects of Urban Form. University of Wisconsin. https://doi.org/10.1016/c2013-0-02616-3

Sahambangun, D. S., Waani, J. O., \& Warouw, F. (2014). Pola Permukiman Rumah Berlabuh Masyarakat Serui Ansus Di Kota Sorong. Media Matrasain, 11(2), 21-31.

Sahambangun, D. S., Waani, J. O., \& Warouw, F. (2015). Makna Ruang Publik Permukiman Rumah Berlabuh Masyarakat Serui Ansus Di Kota Sorong. Media Matrasain, 12(3), 28-34.

Sahambangun, D. S., Warouw, F., \& Waani, J. O. (2015). Makna Ruang Rumah Berlabuh Masyarakat Serui 
Ansus di Kota Sorong. E 119-E 124. https://temuilmiah.iplbi.or.id/wp-content/uploads/2015/11/TI2015E-119-124-Makna-Ruang-Rumah-Berlabuh-Masyarakat-Serui-Ansus-di-Kota-Sorong.pdf

Soukotta, D. (2014). TANDA TERITORI PRIMER RUMAH-RUMAH DI KAMPUNG JAWA TONDANO. 2(2), $116-127$.

Soukotta, D., Waani, J. O., Rogi, O. H. A., Pendahuluan, I., \& Tondano, K. J. (2014). KLASIFIKASI RUANG TERITORI PUBLIK PADA RUMAH-RUMAH DI KAMPUNG JAWA TONDANO Studi Kasus di Lingkungan III. Media Matrasain, 11(2), 61-67. 